\title{
Perbedaan Pengaruh HES 6\% (200) Dalam NaCl 0,9\% dan Dalam Larutan Berimbang pada Base Excess dan Strong Ion Difference Pasien Seksio Sesaria dengan Anestesi Spinal
}

\section{Effect of HES $6 \%$ difference (200) in $0.9 \% \mathrm{NaCl}$ solution and in balanced at Base Excess and Strong Ion Difference cesarean section patients with Spinal Anesthesia}

Djatun Hasyim*, Ratno Samodro*, Himawan Sasongko*, Ery Leksana*

* Bagian Anestesiologi dan Terapi Intensif FK Undip/ RSUP dr. Kariadi, Semarang

\section{ABSTRACT}

Background: On cesarean section with spinal anesthesia, colloid administration as preload is more effective than crystalloid. This preload using colloid with its different solvent has its own effect to the acid base balance. Therefore the use of colloid-solvent -based-on is being improved.

Objectives: to analyze the effect of HES 6\% in balanced solution with $\mathrm{HES} 6 \%$ in $\mathrm{NaCl}$ $0,9 \%$ on Base Excess (BE) and Strong Ion Difference (SID) on cesarean section patients with spinal anesthesia.

Method: this is an experimental clinical trial, double blind randomized with consecutive sampling, divided into two groups $(n=12)$, HES $6 \%$ in balanced solution and $\mathrm{HES} 6 \%$ in $\mathrm{NaCl} 0,9 \%$. Statistical analysis were performed with SPSS for Windows version 16.

Result: Group HES 6\% in $\mathrm{NaCl} 0,9 \%$ has significant difference for BE before and after administration $(p<0,05)$. While BE before and after administration on HES $6 \%$ in balanced solution has insignificant difference ( $p>0,05)$. Group $\mathrm{HES} 6 \%$ in $\mathrm{NaCl}$ $0,9 \%$ has significant difference for SID before and after administration $(p<0,05)$. While SID before and after administration on HES $6 \%$ in balanced solution has insignificant difference ( $p>0,05)$.

Conclusion: there are significant declination of BE and SID on group of HES $6 \%$ in $\mathrm{NaCl}$ 0,9\% than on group of HES 6\% in balanced solution.

Keyword: HES 6\%, balanced solution, $\mathrm{NaCl} 0,9 \%, \mathrm{BE}$, SID

\section{ABSTRAK}

Latar belakang: Pada bedah sesar dengan anestesi spinal, pemilihan koloid sebagai cairan preload lebih efektif ketimbang kristaloid. Pemberian cairan koloid dengan pelarut yang berbeda sebagai preload ini memiliki dampak terhadap keseimbangan asam basa tubuh. Sehingga pemilihan koloid berdasarkan pelarutnya mulai 
dipertimbangkan.

Tujuan: Melihat pengaruh pemberian HES $6 \%$ dalam larutan berimbang dengan HES $6 \%$ dalam NaC1 0,9\% terhadap Base Excess (BE) dan Strong Ion Difference (SID) pada pasien bedah sesar dengan anestesi spinal.

Metode: Merupakan uji klinik eksperimental yang dilakukan secara acak tersamar ganda, dengan consecutive sampling, dibagi menjadi 2 kelompok (n=12) yaitu kelompok HES 6\% dalam larutan berimbang dan HES 6\% dalam NaC1 0,9\%. Uji statistik untuk membandingkan nilai BE dan SID pada masing-masing kelompok menggunakan SPSS for Windows versi 16

Hasil: Nilai BE sebelum dan sesudah perlakuan pada kelompok HES 6\% dalam NaCI 0,9\%, memiliki perbedaan yang bermakna $(p<0,05)$. Sedangkan nilai BE sebelum dan sesudah perlakuan pada kelompok HES $6 \%$ dalam larutan berimbang memiliki perbedaan yang tidak bermakna ( $p>0,05)$. Nilai SID sebelum dan sesudah perlakuan pada kelompok HES 6\% dalam NaC1 0,9\%, memiliki perbedaan yang bermakna ( $p$ 0,05). Sedangkan nilai SID sebelum dan sesudah perlakuan pada kelompok HES 6\% dalam larutan berimbang memiliki perbedaan yang tidak bermakna ( $p>0,05)$.

Kesimpulan: Terdapat penurunan BE dan SID secara bermakna pada kelompok HES '6\% dalam NaC1 0,9\% dibanding pada kelompok HES 6\% dalam larutan berimbang.

Kata Kunci: HES 6\%, larutan berimbang, NaC1 0,9\%, BE, SID

\section{PENDAHULUAN}

Anestesi spinal merupakan salah satu teknik yang paling sering dipilih pada operasi bedah sesar. Salah satu efek samping yang paling sering dijumpai pada teknik anestesi spinal adalah terjadinya hipotensi. Hal ini sebagai akibat blok simpatis dari obat anestesi lokal yang bekerja di dalam ruang subarakhnoid adalah terjadinya hipotensi. Sebagian besar parturien akan mempunyai mekanisme kompensasi yang cukup untuk memelihara tekanan darah arteri. Hipotensi yang terjadi pada parturien (dengan kondisi tekanan intra abdominal tinggi) akan menyebabkan insidesi penurunan tekanan darah $\pm 20 \%$ lebih sering dibandingkan pada pasien lainnya. ${ }^{1}$
Aliran darah uterus secara langsung ditentukan oleh tekanan darah maternal. Karena itu hipotensi akibat anestesi spinal yang tidak dikelola dengan baik akan berpengaruh buruk pada ibu dan janin. Beberapa tindakan dapat dilakukan untuk mencegah dan mengatasi hipotensi yang terjadi, antara lain dengan meningkatkan preload, atau pemberian vasopressor.

Hasil ulasan system review spinal analgesia menunjukkan bahwa kemampuan pemberian kristaloid sebagai cairan preloading untuk mencegah hipotensi tidak konsisten dan dalam hal ini koloid lebih efektif ketimbang kristaloid. ${ }^{2,3}$ Penelitian Riley 
dkk menunjukkan hipotensi lebih sedikit terjadi pada kelompok yang mendapat preload $500 \mathrm{ml}$ Hydroxyethyl Starch (HES) 6\% dibandingkan kelompok yang mendapat preload 1 liter Ringer Laktat. $^{4,5}$

Awal tahun 1970-an cairan yang mengandung $\mathrm{NaCl} 0,9 \%$ dikenal sebagai cairan isotonik paling fisiologis, namun kini didapatkan data bahwa terjadi perubahan substansial asam-basa pada pemberian dalam jumlah besar cairan infus $\mathrm{NaCl} 0,9 \%$, keadaan ini disebut sebagai kondisi "asidosis hiperkloremik". 6,7

Kebijakan untuk memilih cairan dengan mempertimbangkan dampak terhadap keseimbangan asam-basa mulai dikembangkan. Terjadinya gangguan pada keseimbangan asam-basa dapat mengakibatkan disfungsi organ penting seperti edema otak, kejang, gangguan kontraksi jantung, vasodilatasi pembuluh darah paru dan vasodilatasi sistemik. Beberapa penelitian juga menjelaskan bahwa pemberian dalam jumlah relatif besar cairan yang tidak mengandung elektrolit berimbang dikatakan mempunyai tendensi memperberat kondisi asidosis yang semula mungkin sudah ada karena sebuah proses hipoperfusi. ${ }^{8}$

Beberapa tipe cairan koloid yang saat ini beredar di pasaran dengan berbagai karakteristik berdasarkan berat molekul (BM) dan derajat substitusinya. Cairan yang memiliki BM besar akan bertahan lebih lama dalam ruang intravaskuler sedangkan derajat substitusi berpengaruh pada koagulasi darah. Saat ini jenis koloid yang mengandung larutan berimbang mulai banyak diminati.

Hal tersebut mendorong dilakukannya penelitian ini, untuk membuktikan pemberian preload pada anestesi spinal menggunakan cairan koloid uang mengandung $\mathrm{NaCl} \quad 0,9 \% \quad$ bila dibandingkan dengan cairan koloid yang mengandung pelarut larutan berimbang akan menimbulkan perubahan kadar klorida yang bermakna, serta mempengaruhi kondisi keseimbangan asam basa yang dapat dilihat dari nilai strong ion difference (SID) dan base excess (BE) pada pemeriksaan analisa gas darah.

\section{METODE}

Penelitian ini merupakan uji klinik eksperimental tahap II yang dilakukan secara acak tersamar ganda, dengan tujuan mencari perbedaan pengaruh pemberian 15 cc/kgBB HES 6\% (200) dalam larutan $\mathrm{NaCl} 0,9 \%$ dengan $15 \mathrm{cc}$ kgBB HES 6\% (200) dalam larutan berimbang terhadap komponen keseimbangan asam basa.

Seleksi penderita dilakukan pada saat kunjungan preoperasi, penderita yang memenuhi kriteria ditentukan sebagai sampel. Kriteria inklus meliputi Usia parturien 19-35 tahun, status fisik ASA I - ASA II, menjalani operasi bedah sesar cito dan elektif dengan anestesi spinal, BMI normal (18,5-24,9), setuju untuk diikutsertakan dalam penelitian. Kriteria 
eksklusi meliputi pasien yang mendapat pemberian cairan koloid $>15 \mathrm{cc} / \mathrm{kgBB}$, pasien yang mendapat pemberian transfusi darah selama perlakuan, pasien yang durante operasi mengalami komplikasi anestesi maupun pembedahan seperti: kesadaran menurun; penurunan $\mathrm{SpO}_{2}$ (keadaan umum sesak sampai dengan apneu); perdarahan tidak terkontrol lebih dari $500 \mathrm{ml}$.

Sampel diambil dari pasien yang menjalani operasi bedah sesar dan dibagi menjadi dua kelompok. Kelompk 1 (K1) menggunakan $15 \mathrm{cc} / \mathrm{kgBB}$ HES $6 \%$ (200) dalam larutan berimbang sebagai preload anestesi spinal, dan Kelompok 2 (K2) menggunakan $15 \mathrm{cc} /$ $\mathrm{kgBB}$ HES 6\% (200) dalam larutan $\mathrm{NaCl} 0,9 \%$ sebagai preload anestesi spinal.

Penelitian dilakukan terhadap 24 pasien yang sebelumnya telah mendapat penjelasan dan setuju untuk mengikuti semua prosedur penelitian. Semua pasien dipuasakan 6 jam dan tidak diberikan obat premedikasi.

Satu jam sebelum operasi dilakukan pemeriksaan Analisis Gas Darah (AGD) dengan mengambil sampel $1 \mathrm{cc}$ darah arteri dan pemeriksaan elektrolit $\left(\mathrm{Na}^{+}\right.$; $\mathrm{K}^{+}, \mathrm{Cl}^{-}$) dengan mengambil sampel $3 \mathrm{cc}$ darah vena. Hasil pemeriksaan awal tersebut digunakan sebagai data dasar.

Lima belas menit sebelum dilakukan anestesi spinal, diberikan preload $15 \mathrm{cc} /$ kgBB HES 6\% (200) dalam larutan berimbang untuk 12 sampel dan $15 \mathrm{cc} /$ kgBB HES 6\% (200) dalam larutan $\mathrm{NaCl}$ $0,9 \%$ untuk 12 sampel lainnya.

Anestesi spinal dilakukan dengan jarum spinal 25G pada celah vertebra lumbal 3 -4 . Setelah keluar cairan serebrospinalis sebagai tanda pasti bahwa ujung jarum spinal berada dalam ruang subarachnoid, dilakukan injeksi bupivacain heavy 0,5\% 3 cc dengan kecepatan 1 cc/detik. Setelahnya, penderita sesegera mungkin dibaringkan dalam posisi terlentang horizontal dengan kepala diganjal bantal serta diberikan $\mathrm{O}_{2} 3 \mathrm{lt} /$ menit.

Tinggi blok sensorik ditentukan dengan cara pinprick menggunakan jarum $22 \mathrm{G}$ bevel pendek. Setelah anestesi spinal berhasil, operasi sesar dapat dimulai. Bila dalam lima belas menit tidak terjadi blok (negatif), maka anestesi spinal dianggap gagal dan pasien dikeluarkan dari penelitian dan dilanjutkan dengan general anesthesia.

Satu jam setelah pemberian preload 15 cc/kgBB cairan HES 6\% (200) pada masing-masing kelompok lalu dilakukan pemeriksaan BGA dan elektrolit $\left(\mathrm{Na}^{+}\right.$; $\mathrm{K}^{+}, \quad \mathrm{Cl}^{-}$). Hasil pemeriksaan dibandingkan dengan data awal dan dilakukan analisis statistik menggunakan piranti lunak SPSS for Windows versi 16.

\section{HASIL}

Telah dilakukan penelitian tentang pengaruh pemberian $15 \mathrm{cc} / \mathrm{kgBB}$ HES $6 \%$ (200) dalam larutan berimbang dengan $15 \mathrm{cc} / \mathrm{kgBB}$ HES 6\% (200) dalam $\mathrm{NaCl} 0,9 \%$ terhadap BE dan SID 
pada 24 orang parturien yang menjalani bedah sesar dengan anestesi spinal dengan status fisik ASA I dan II setelah disesuaikan dengan kriteria inklusi dan eksklusi yang ditentukan. Karakteristik subjek penelitian ditampilkan pada Tabel 1

Tabel 2 menunjukkan bahwa nilai BE sebelum dan sesudah perlakuan pada kelompok HES 6\% (200) dalam $\mathrm{NaCl}$ $0,9 \%$, memiliki perbedaan yang bermakna. Sedangkan nilai BE sebelum dan sesudah perlakuan pada kelompok HES 6\% (200) dalam larutan berimbang memiliki perbedaan yang tidak bermakna. Perbandingan nilai $\mathrm{BE}$ sebelum perlakuan antara kelompok HES 6\% (200) dalam larutan berimbang dengan HES 6\% (200) dalam $\mathrm{NaCl}$ $0,9 \%$ memiliki perbedaan yang bermakna, demikian pula nilai BE sesudah perlakuan pada dua kelompok tersebut memiliki perbedaan yang bermakna.

Tabel 3 menunjukkan bahwa nilai SID sebelum dan sesudah perlakuan pada kelompok HES 6\% (200) dalam $\mathrm{NaCl}$ $0,9 \%$, memiliki perbedaan yang bermakna. Sedangkan nilai SID sebelum dan sesudah perlakuan pada kelompok HES 6\% (200) dalam larutan berimbang memiliki perbedaan yang tidak bermakna. Perbandingan nilai SID sebelum perlakuan antara kelompok HES 6\% (200) dalam larutan berimbang dengan HES 6\% (200) dalam $\mathrm{NaCl}$ $0,9 \%$ memiliki perbedaan yang tidak bermakna, sedangkan pula nilai SID sesudah perlakuan pada dua kelompok tersebut memiliki perbedaan yang bermakna.

\section{PEMBAHASAN}

Pada karakteristik umum dari subjek kedua kelompok penelitian yang ada, yaitu umur, BMI, status fisik (ASA), setelah dilakukan uji beda didapatkan perbedaan yang tidak bermakna di antara keduanya sehingga kedua kelompok layak untuk dibandingkan . Hal tersebut ditunjukkan pada Tabel 1.

Tabel 2 menunjukkan bahwa bahwa nilai BE sebelum dan sesudah perlakuan pada kelompok HES 6\% (200) dalam larutan berimbang memiliki perbedaan yang tidak bermakna. Nilai BE sebelum dan sesudah perlakuan pada kelompok HES 6\% (200) dalam $\mathrm{NaCl} \quad 9,0 \%$ memiliki perbedaan yang bermakna.

Base Excess merupakan variabel yang spesifik untuk menentukan komponen metabolik pada gangguan asam basa yang terjadi. Berdasarkan nomogram yang dikembangkan oleh SiggaardAnderson, didapatkan bahwa BE akan berubah sesuai komponen metabolik yang terganggu dari keseimbangan asam basa tubuh. ${ }^{9}$

Secara fisiologis, wanita hamil berada dalam kondisi lebih asidosis. Hal ini menjelaskan mengapa, pada kelompok HES $6 \%$ (200) dalam $\mathrm{NaCl} \quad 0,9 \%$ maupun HES 6\% (200) dalam larutan berimbang, nilai $\mathrm{BE}$ sebelum perlakuan berada dalam kondisi asidosis (BE kurang dari -2). Namun bila dibandingkan dengan kondisi setelah 
Tabel 1. Karakteristik Umum Subyek Penelitian

\begin{tabular}{|c|c|c|c|}
\hline Variabel & HES NS & HES BS & $\mathbf{p}$ \\
\hline Umur & $28,33 \pm 5,015$ & $28,08 \pm 4,907$ & $0,903 *$ \\
\hline \multicolumn{4}{|l|}{ ASA } \\
\hline I & $6(25,0 \%)$ & $7(29,2 \%)$ & $0,682 * *$ \\
\hline II & $6(25,0 \%)$ & $5(20,8 \%)$ & \\
\hline BMBMI & $22,12 \pm 1,801$ & $22,48 \pm 1,524$ & $0,604 *$ \\
\hline
\end{tabular}

Tabel 2. Perbedaan pengaruh pemberian HES 6\% (200) dalam larutan berimbang dan HES 6\% (200) dalam $\mathrm{NaCl} 0,9 \%$ terhadap perubahan $\mathrm{BE}$

\begin{tabular}{llll}
\hline Variabel & BE pre & BE post & p \\
\hline HES NS & $-6,59 \pm 1,549$ & $-7,83 \pm 2,086$ & $0,003^{* *}$ \\
HES BS & $-3,26 \pm 0,680$ & $-2,97 \pm 0,597$ & $0,216^{* *}$ \\
\hline $\mathrm{p}$ & $0,000^{*}$ & $0,000^{*}$ & \\
\hline
\end{tabular}

Tabel 3. Perbedaan pengaruh pemberian HES 6\% (200) dalam larutan berimbang dan HES 6\% (200) dalam $\mathrm{NaCl} 0,9 \%$ terhadap perubahan SID

\begin{tabular}{llll}
\hline Variabel & SID pre & SID post & p \\
\hline HES NS & $37,48 \pm 2,368$ & $34,38 \pm 2,758$ & $0,000^{* *}$ \\
HES BS & $37,75 \pm 1,215$ & $38,00 \pm 1,206$ & $0,555^{* *}$ \\
\hline $\mathrm{p}$ & $0,732^{*}$ & $0,000^{*}$ & \\
\hline
\end{tabular}


perlakuan, pada kelompok HES 6\% (200) dalam larutan berimbang didapatkan perubahan $\mathrm{BE}$ yang tidak bermakna, dengan kecenderungan adanya perbaikan nilai BE. Ini dimungkinkan karena pada HES 6\% (200) dalam larutan berimbang terdapat anion laktat yang di dalam tubuh akan dimetabolisme menjadi bikarbonat yang pada gilirannya akan memperbaiki kelainan pada keseimbangan asam basa dengan cara mengintervensi persamaan asam-basa. Pada penelitian ini didapatkan penurunan nilai BE yang bermakna secara statistik pada kelompok yang diberikan preload HES $6 \%$ (200) dalam $\mathrm{NaCl} 0,9 \%$ yang berarti keseimbangan asam basa terganggu ke arah asidosis metabolik.

Menurut Stewart status asam basa cairan tubuh ditentukan oleh beberapa variabel independen. Dalam plasma darah, variabel independen tersebut adalah $\mathrm{pCO}_{2}$, SID, konsentrasi total asam lemah non-volatile (albumin, fosfat). ${ }^{10}$

Difusi $\mathrm{CO}_{2}$ melewati membran sangat mudah dan cepat, sehingga setiap perubahan yang terjadi pada $\mathrm{pCO}_{2}$ akan cepat diatasi oleh perubahan ventilasi. Dengan demikian perubahan pada $\mathrm{pCO}_{2}$ tidak akan menyebabkan terjadinya perbedaan konsentrasi $\left[\mathrm{H}^{+}\right]$dari masing -masing kompartemen, sehingga $\mathrm{CO}_{2}$ tidak berkontribusi dalam menyebabkan perbedaan status asam basa antar membran.

SID didapatkan dari $\mathrm{Na}^{+}$dan $\mathrm{Cl}^{-}$. Secara lebih spesifik dapat dikatakan bahwa karena $\mathrm{Na}^{+}$berperan penting pada tonisitas, maka peran $\mathrm{Cl}^{-}$menjadi lebih dominan dibanding $\mathrm{Na}^{+}$dalam menentukan $\mathrm{pH}$ cairan ekstrasel. Dari sketsa Jonathan Waters ditunjukkan bahwa setiap perubahan komposisi elektrolit dalam suatu larutan akan menghasilkan perubahan pada $\left[\mathrm{H}^{+}\right]$atau $\left[\mathrm{OH}^{-}\right]$dalam rangka mempertahankan prinsip kenetralan muatan listrik (electrical neutrality). ${ }^{11}$

Menurut Stewart, peran ginjal dalam menurunkan $\left[\mathrm{H}^{+}\right]$dalam plasma terjadi akibat regulasi tubuh terhadap SID (terutama $\left[\mathrm{Cl}^{-}\right]$) melalui tubulus ginjal. Ion klorida akan difiltrasi namun tidak direabsorpsi oleh tubuh sehingga nilai SID dalam plasma dijaga tetap seimbang. Sehingga proses amoniagenesis di ginjal berfungsi untuk menghasilkan $\mathrm{NH}_{4}^{+}$yang kemudian dapat mengikat $\mathrm{Cl}^{-}$agar dapat diekskresikan dalam bentuk $\mathrm{NH}_{4} \mathrm{Cl}$, bukan karena sifat amonia yang dapat mengangkut $\mathrm{H}^{+}{ }^{10}$

Dari hasil penelitian, SID sebelum perlakuan antara kelompok HES 6\% (200) dalam $\mathrm{NaCl} 0,9 \%$ dengan HES $6 \%$ (200) dalam larutan berimbang didapatkan adanya perbedaan yang tidak bermakna. Ini berarti selisih antara $\mathrm{Na}^{-}$ dan $\mathrm{Cl}^{-}$sebelum perlakuan pada kedua kelompok berada dalam kondisi yang tidak jauh berbeda, atau dapat dikatakan dalam kondisi metabolik yang cenderung sama. Namun pada pemeriksaan SID setelah perlakuan antara kelompok HES 6\% (200) dalam 
$\mathrm{NaCl} \quad 0,9 \%$ dengan HES 6\% (200) dalam larutan berimbang didapatkan adanya perbedaan yang bermakna ( $\mathrm{p}<$ $0,05)$. Kondisi yang mengakibatkan hal ini adalah pada kelompok HES 6\% (200) dalam $\mathrm{NaCl} 0,9 \%$, pelarutnya memiliki komposisi $\mathrm{Na}^{+}$dan $\mathrm{Cl}^{-}$yang besar, yang pada akhirnya akan mengakibatkan penurunan nilai SID dan mengganggu keseimbangan asambasa ke arah asidosis metabolik.

Pada penelitian ini terdapat perbedaan yang tidak bermakna pada pemeriksaan SID antara sebelum dengan sesudah perlakuan pada kelompok HES 6\% (200) dalam larutan berimbang ( $\mathrm{p}>$ 0,05). Karena pada kelompok ini terdapat kandungan $\mathrm{Na}^{+}$dan $\mathrm{Cl}^{-}$yang mendekati komposisi plasma, tidak banyak terjadi perubahan SID yang mengindikasikan gangguan keseimbangan asam-basa. Namun begitu terdapat perbedaan yang bermakna dari penurunan nilai SID pada kelompok yang diberikan preload HES 6\% (200) dalam $\mathrm{NaCl} 0,9 \%$ yang berarti keseimbangan asam basa mengarah ke asidosis metabolik.

Pada penelitian ini tidak memeriksa komponen lain dari penilaian asam-basa menurut metode Stewart seperti free water, albumin effect, maupun unmeasured anion dikarenakan adanya beberapa keterbatasan, antara lain sarana dan dana penelitian. Total sampel yang diperiksa sejumlah 24 pasien dikarenakan keterbatasan waktu penelitian. Hal ini mungkin berakibat kurang validnya data penelitian yang didapatkan dibanding apabila penelitian ini mengambil jumlah sampel yang lebih banyak. Terkait dengan etika dan keselamatan pasien, pada penelitian ini dibatasi hanya pada operasi bedah sesar dengan perdarahan kurang dari $500 \mathrm{ml}$.

\section{SIMPULAN}

Terdapat penurunan BE secara bermakna pada kelompok $15 \mathrm{cc} / \mathrm{kgBB}$ HES $6 \%$ (200) dalam $\mathrm{NaCl} \quad 0,9 \%$ dibandingkan kelompok $15 \mathrm{cc} / \mathrm{kgBB}$ HES 6\% (200) dalam larutan berimbang dan terdapat penurunan SID secara bermakna pada kelompok $15 \mathrm{cc} / \mathrm{kgBB}$ HES $6 \%$ (200) dalam $\mathrm{NaCl} \quad 0,9 \%$ dibandingkan kelompok $15 \mathrm{cc} / \mathrm{kgBB}$ HES 6\% (200) dalam larutan berimbang.

\section{DAFTAR PUSTAKA}

1. Birnbach DJ, Browne IM. Anesthesia for obstetrics. Dalam: Miller RD. Miller's anesthesia. Edisi 6. Pennsylvania: Elsevier Churchill Livingstone; 2005. Hlm.326-29.

2. Mulyono I, Harijanto E, Sunatrio S. Cairan koloid. Dalam: Panduan tata laksana terapi cairan perioperatif. Jakarta: Perhimpunan dokter spesialis anestesiologi dan reanimasi Indonesia; 2009. HIm. 130-31.

3. Abdelrachman RS, Elzeftawy AE. Comparison of colloid versus crystalloid preload for prevention of hypotension during spinal anesthesia for elective section cesarean. Tanta Med Sciences J. 2007; 2(1): 134-41.

4. Riley ET, Cohen SE, Rubenstein AJ, Flanagan B. Prevention of hypotension after spinal anesthesia for cesarean section: six percent hetastarch versus lactated ringer's 
solution. AnestAnalg. 1995; 81(4): 838-42.

5. Ueyama H, Le H, Tanigami H, Mashimo $\mathrm{T}$, Yoshiva I. Effect of crystalloid and colloid preload on blood volume in the parturient undergoing spinal for elective cesarean section. Anesthesiology. 1999; 91; 1571-6.

6. Zander R. Fluid Management [e-book]. Germany: Bibliomed; 2006 [diunduh 6 January 2012]. Tersedia dari: www.physioklin.de

7. Ery leksana. SIRS, Sepsis, keseimbangan asam basa, shock dan terapi cairan. Semarang: SMF/Bag. Anestesi dan terapi intensif RSUP Dr. Kariadi/Fak. Kedokteran UNDIP. 2006.
8. Brill SA, Stewart TR, Brundage SI, Schreiber MA. Base deficit does not predict mortality when secondary to hyperchloremic acidosis. Shock. 2002; 17; 459-62.

9. Kellum JA. Diagnosis and treatment of acidbase didorders. Dalam: Grenvik A, Shoemaker PK, Ayer S, Holbrook. Textbook of critical care. Philadelphia: WB Saunders; 1999. Hlm. 839-53.

10. Finucane BT. Complications of regional anesthesia. New York: Churchill Livingstone; 2000.

11. Mustafa I, George YWH. Keseimbangan asam-basa (paradigma baru). Anest and critcare. $2003 ; 21$ : 1-13. 